\title{
Modelling hydrate deposition and sloughing in gas-dominant pipelines
}

\author{
Mauricio Di Lorenzo, ${ }^{1,2, *}$ Zachary M. Aman, ${ }^{2}$ Karen Kozielski, ${ }^{1}$ Bruce W.E. Norris, ${ }^{2}$ Michael L. Johns, ${ }^{2}$ \\ Eric F. May ${ }^{2, *}$ \\ [1] CSIRO Energy, 26 Dick Perry Avenue, Kensington WA 6151, Australia \\ [2] Fluid Science and Resources Division, School of Mechanical and Chemical Engineering, University \\ of Western Australia, 35 Stirling Hwy, Crawley WA 6009, Australia
}

\begin{abstract}
We present a model for hydrate deposition and sloughing in gas dominated pipelines which allows for rapid estimations of the pressure and temperature profiles along a horizontal pipeline during normal operation in the hydrate forming region in the presence of monoethylene glycol (MEG). Previous models assume that the hydrate deposit growing at the pipe wall is stable, which may lead to an overestimation of the pressure drop over time. Hydrate growth rates were calculated using a classical hydrate kinetic model combined with a simplified two-phase flow model for pipelines in the annular flow regime with droplet entrainment. Hydrate growth at the pipe wall, deposition of hydrate particles from the gas stream and sloughing due to shear fracture of the deposited film contributed to the evolution of the hydrate deposit. The model parameters included a scaling factor to the kinetic rate of hydrate growth and a particle deposition efficiency factor. The fraction of deposited particles forming a stable hydrate film at the pipe wall through sintering and the shear strength of the deposit were introduced as two additional parameters to enable simulation of sloughing events. The tuned model predicted hydrate formation within $40 \%$ and pressure drop within 50\% of measurements previously obtained in a gas-dominated flow loop over a wide range of subcoolings, MEG concentrations and high and intermediate gas velocities. The observed decrease of the kinetic factor with decreasing gas velocity indicated larger resistances to hydrate growth
\end{abstract}


in the entrained droplets at lower flow rates, while the increase of the deposition parameter with MEG concentration was consistent with a particle adhesion/cohesion mechanism based on the formation of a capillary bridge. The preliminary sloughing model presented in this work, combined with flowloop testing, has allowed the first in-situ determinations of the effective shear strength of the hydrate deposits (in the range of 100 to $200 \mathrm{~Pa}$ ) which is a key property to predict hydrate detachment and accumulation in gas-dominated pipelines.

Keywords: gas hydrates; gas pipelines; flowloop; deposition; sloughing

\section{Introduction}

Gas hydrates are ice-like crystals stabilized by inclusion of small gas molecules inside cavities formed by hydrogen-bonded water molecules. At a low temperature of $4{ }^{\circ} \mathrm{C}\left(39.2^{\circ} \mathrm{F}\right)$, natural gas in the presence of water can form hydrates at pressures above 1.25 MPa (181 psi), while at higher pressures the hydrate formation temperature can far exceed $4{ }^{\circ} \mathrm{C}$ [1]. Such pressure and temperature conditions are commonly found in deep subsea oil and gas pipelines where the occurrence of hydrate blockages has been reported during both transient [2] and steady pipeline flow [3]. As plug remediation operations are often complex, lengthy and can pose serious safety hazards, hydrate prevention has become a primary concern in hydrocarbon production.

The preferred method to avoid hydrate formation in offshore fields is based on continuous injection of thermodynamic inhibitors (THIs), such as mono-ethylene glycol (MEG) and methanol. These chemicals effectively prevent hydrate crystallization by reducing the activity of water [1], but large volumes of THIs are required to treat high water cut systems that are exposed to high subcoolings. MEG-based hydrate inhibition can be a major cost driver in offshore oil and gas projects where water production is expected to increase significantly over time [4]. To improve cost efficiencies, hydrate management methods have been proposed by which limited volumes of hydrates are allowed to form without severely impairing 
pipeline flow [5,6]. A major limitation to this approach, however, is the lack of validated models capable of predicting under what circumstances hydrate blockages will form in pipelines.

Besides pressure and temperature conditions, the risk of plug formation depends mainly on the type of fluids prevalent in the pipeline (water or hydrocarbon), the liquid holdup and the flow regime [7]. So far most of the research has focused on liquid-dominated systems. A plug-in module for hydrate kinetics and transport in oil-dominated pipelines [8] has been incorporated into a multiphase flow simulator to predict the pipeline pressure drop increase due to fluid viscosification caused by the agglomeration of hydrate particles. Using a similar approach, more recently a stand-alone software was developed for rapid screening of the risk of hydrate blockages in oil-dominated systems [9].

In gas-dominated systems, plugging is primarily determined by the extent of hydrate deposition at the pipe wall. During field tests conducted in gas-condensate pipelines operating at hydrate forming conditions, the pressure drop showed first a gradual increase, followed by cycles of build-up and collapse before a complete blockage occurred [10] . Based on these observations, Lingelem et al. [11] proposed a conceptual picture for hydrate blockages in gas-dominated flowlines, which was further developed by Sloan [12]. According to this model, the gradual rise of the pressure drop over time was produced by the formation and growth of a solid layer of hydrates on the pipe wall, which expanded radially narrowing the cross section of the flow line (“stenosis”). The large pressure drop fluctuations preceding pipeline blockage were attributed to the mechanical failure of the deposited layer ("sloughing”) when the local shear stress applied by the pipeline fluids became sufficiently large .

Several recent efforts have focused on developing models and gathering experimental data on the complex mechanisms that lead to hydrate blockages in gas pipelines. A numerical model for hydrate formation in wet-gas pipelines was formulated by Shagapov et al. [13], which included the effect of methanol injection. Nicholas et al. [14] carried out flowloop experiments and modelling of hydrate and ice deposition in a water-saturated condensate phase, while Rao et al. [15] studied hydrate deposition from a water-saturated gas flowing over the surface of a cold tube. In each of these studies, the systems considered could be approximated as consisting of a fluid single-phase, with hydrate formation being 
limited by water availability. Consequently, the effect of hydrate deposition could be measured only after long periods of time.

Multiphase flow experiments were conducted by Dorstewitz et al. [16] using a gaseous refrigerant capable of hydrate formation and liquid water in a low pressure flow loop equipped with a photographic system for direct observation of the annular hydrate layer. The authors developed an analytical model to define the conditions for the stability of the hydrate layer formed under heat transfer limitations. Multiphase flowloop data for systems comprised of natural gas with water at low holdup and hydrate forming conditions have become available more recently. Di Lorenzo et al. [17,18] investigated the effect of the subcooling on hydrate formation and transport in the annular flow regime using a gas-dominated flowloop. In these experiments the pressure drop behaviour was interpreted as a combination of a stenosis-type growth followed by deposit sloughing. At subcoolings below $6 \mathrm{~K}\left(10.8{ }^{\circ} \mathrm{F}\right)$, the pressure drop traces were relatively smooth and could be fitted to a variable hydraulic diameter model which assumed constant growth rate of the annular hydrate deposit. At higher subcoolings, faster hydrate formation rates induced a more complex behaviour characterized by fast pressure drop oscillations, produced by a pipe jamming and release mechanism. Cassar et al. [19] and Sinquin et al. [20] performed flow loop tests in gas-dominated conditions to investigate the effect of the flow regime (stratified vs annular) and the presence of a condensate phase on hydrate formation and pipeline plugging. In these experiments hydrate formation was observed to start at a low subcooling of about $1 \mathrm{~K}\left(1.8^{\circ} \mathrm{F}\right)$, followed by the growth of a hydrate crust at the pipe wall and the appearance of hydrate chunks that produced significant flow instabilities over the course of the experiments. Higher formation rates were measured in annular flow compared to stratified flow regimes, which led to shorter blockage times. Recently Wang et al. [21] formulated a model for hydrate formation and deposition in gas-dominated systems with free water, which was applied to the study of hydrate blockages in vertical gas wells. This model was later refined [22] to account for the effect of hydrate particle deposition from the gas stream through the introduction of an empirical parameter to better match the flow loop data of Di Lorenzo et al. [17]. The 
models developed so far could only predict a continuous growth of the hydrate deposit over time (increasing pressure drop) and therefore are not applicable when sloughing is present.

In this work we present a model for hydrate deposition and sloughing in gas dominated systems, which allows for rapid estimations of the pressure and temperature variations along a horizontal pipeline operating in the annular flow regime at hydrate forming conditions. This work improves previous models which assume continuous growth of the hydrate deposit and tend to over-estimate the pressure drop when the deposit may not be mechanically stable. Key mechanisms were integrated in this model to determine the evolution of the hydrate deposit at the pipe wall. These included: hydrate formation at the wetted pipe perimeter, particle deposition from the gas stream and shear induced sloughing of the deposited film. The physical parameters used in this predictive model were tuned to match estimates of the hydrate formation and pressure drop previously measured using a single-pass, gas-dominated flowloop where the subcoolings, MEG dosage and gas velocity were varied [17,18,23]. The introduction of a preliminary mechanism for sloughing in the model enabled the first in-situ determinations of the effective shear strength of the hydrate deposit formed in these gas-dominant flowloop experiments.

\section{Model Description}

\subsection{Main Assumptions}

The model applies to gas-dominated systems composed by natural gas, water and MEG as a hydrate inhibitor. At typical gas and liquid flow rates, the liquid volume fraction in the pipe (holdup) is less than $10 \%$ and the flow regime is annular with the liquid phase forming a film at the pipe wall and small droplets entrained in the gas core. The model further develops the conceptual description for hydrate blockages in gas-dominant systems initially proposed by Lingelem et al. [11] and extended by Sloan, [12], illustrated in Figure 1. Besides deposition by crystallization, previously considered in the cited models, in this work we have incorporated the deposition of hydrate particles formed in the entrained droplets as a key mechanism of hydrate build-up at the pipe walls. 
One major simplifying assumption of the model is that the pipeline fluids and hydrates are distributed uniformly across the pipe section and in particular, the hydrate deposit is assumed to form a concentric annulus which grows radially inwards. Compositional changes in the gas phase due to hydrate formation are not considered at this stage, whereas the MEG concentration is tracked by calculating the water consumption along the flowline.

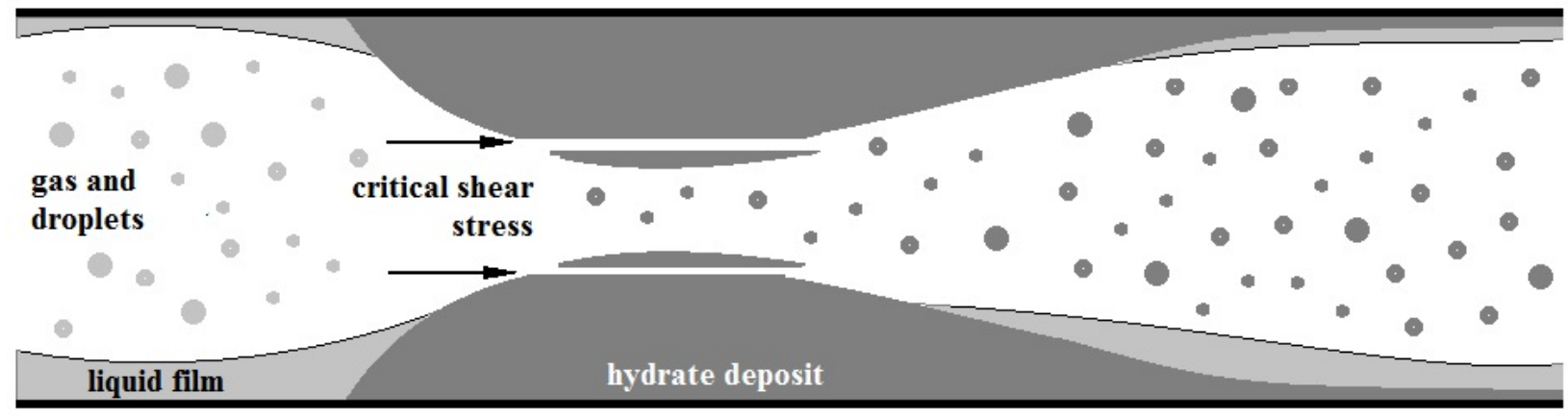

Figure 1. Geometry and phase distribution in a pipe section showing the liquid film and entrained droplets in the gas stream and the hydrate deposit at the point of sloughing.

\subsection{Momentum and Energy Balance}

A further simplification is used in the calculation of the pressure drop, where the pipeline fluids are treated as a pseudo one-phase fluid, following the well-known method proposed by Beggs and Brill [24]. From the momentum balance equation, the authors derived the following steady-state expression for the pressure gradient in a gas-liquid horizontal pipeline:

$\frac{\Delta P}{\Delta x}=\frac{1}{2} \cdot f \cdot \rho_{\mathrm{ns}} \cdot \frac{v_{\mathrm{m}}^{2}}{D_{\mathrm{h}}}$

where $\Delta P$ is the pressure drop, $\Delta x$ is the length of the pipe section, $f$ is the friction factor, $\rho_{\mathrm{ns}}$ is the no-slip fluid density (defined in terms of the input volumetric flow rates), $v_{\mathrm{m}}$ the fluid mixture velocity and $D_{\mathrm{h}}$ is the hydraulic diameter of the pipe. Full details of the derivation of this equation are provided in the original reference [24]. 
In our model a quasi-stationary approximation is introduced, whereby the hydraulic diameter of the pipeline is allowed to slowly decrease over time due to the formation and growth of a solid deposit at the pipe wall. Other hydrate-related effects on the fluid viscosity, density and friction factors are neglected at this stage.

By applying energy balance to a control volume in the pipeline, following Alves et al. [25], the following expression for the temperature gradient can be derived:

$\frac{\Delta T}{\Delta x}=\beta_{\mathrm{JT}} \cdot \frac{\Delta P}{\Delta x}-\frac{\pi \cdot D_{\mathrm{h}} \cdot U \cdot\left(T-T_{\mathrm{c}}\right)}{\rho_{\mathrm{m}} \cdot c_{\mathrm{m}} \cdot Q_{\mathrm{m}}}+\frac{1}{\Delta x} \cdot \frac{\Delta V_{\mathrm{h}}}{\Delta t} \cdot \frac{\Delta H}{c_{\mathrm{m}} \cdot Q_{\mathrm{m}}}$

In eq. $2 \beta_{\mathrm{JT}}$ is the Joule-Thomson coefficient, $U$ is the overall heat transfer coefficient to the environment, $C_{\mathrm{m}}$ is the heat capacity at constant pressure of the fluid mixture, $Q_{\mathrm{m}}$ is the sum of volumetric flow rates of gas and liquid $\left(Q_{\mathrm{m}}=Q_{\mathrm{g}}+Q_{1}\right), \Delta V_{\mathrm{h}} / \Delta t$ is the hydrate volumetric growth rate and $\Delta H$ is the heat of hydrate formation. The contributions from expansion cooling, heat transfer and heat of hydrate formation are accounted for in the first, second and third term of eq. 2 respectively.

\subsection{Hydrate Formation Model}

The volumetric rate of hydrate formation is calculated using eq. 3, originally derived from a correlation for the rate of gas consumption by hydrates growing in the absence of heat and mass transfer limitations [26].

$\frac{\Delta V_{\mathrm{h}}}{\Delta t}=F_{\mathrm{k}} \cdot \exp \left(C_{1}\right) \cdot \exp \left(-\frac{C_{2}}{T}\right) \cdot \frac{1}{M_{\mathrm{g}} \cdot \rho_{\mathrm{g}}^{\mathrm{h}}} \cdot \Delta T_{\mathrm{sub}} \cdot A$

In eq. $3, \exp \left(C_{1}\right)=37.8$, where $C_{1}$ is the kinetic constant; $C_{2}=13,600 \mathrm{~K}$ is the activation temperature for hydrate formation; $\Delta T_{\text {sub }}$ is the subcooling; $M_{\mathrm{g}}$ and $\rho_{\mathrm{g}}{ }^{\mathrm{h}}$ are, respectively, the average molar mass of the gaseous hydrate formers and their molar density in the hydrate phase; and $A$ is the gas-liquid interfacial area. The empirical coefficient $F_{\mathrm{k}}<1$, has been introduced to account for eventual mass and heat transfer limitations to hydrate growth [26]. 
The expression in eq. 3 assumes that the subcooling $\left(\Delta T_{\mathrm{sub}}=T_{\mathrm{eq}}-T\right)$ is the driving force for the kinetic growth of hydrate crystals. The hydrate equilibrium temperature $T_{\text {eq }}$, which depends on the gas composition, inhibitor concentration and pipeline pressure, can be calculated with good accuracy using commercial programs for multiphase equilibria in the presence of hydrates. To avoid recursive calculations using thermodynamic packages, in this work the subcooling was approximated using the method outlined in Appendix B. For the natural gas composition given in Table 1, at a pressure of 10 MPa and MEG weight concentrations up to $40 \%$, the maximum deviation of the estimated subcooling from that calculated using a multiphase equilibria software with the CPA hydrate model [27] was $0.2{ }^{\circ} \mathrm{C}$.

As hydrates form mainly at the water/gas interface (eq. 3), an accurate estimation of the interfacial area, under the appropriate flow conditions, is critical. In the annular flow regime the gas-liquid interfacial area includes contributions from the entrained droplets and the wetting film. The total area of the droplets, $A_{\text {drop }}$, and the area of the film, $A_{\text {film }}$, in each pipe section are given by:

$A_{\text {drop }}=\frac{3 \pi}{2} \cdot \frac{E \cdot Q_{1}}{S \cdot Q_{\mathrm{g}}} \cdot \frac{D_{\mathrm{h}}^{2} \cdot \Delta x}{d_{32}}$

$A_{\text {film }}=\pi \cdot D_{\mathrm{h}} \cdot \Delta x \cdot \sqrt{1-H+\frac{E \cdot Q_{1}}{S \cdot Q_{\mathrm{g}}}}$

where $E$ is the droplet entrainment, $Q_{1}$ and $Q_{\mathrm{g}}$ are the volumetric flow rates of gas and liquid, $S$ is the ratio between the drop and the gas velocity (slip factor), $d_{32}$ is the Sauter mean diameter of the droplets and $H$ is the liquid holdup. In annular flow conditions the slip factor is usually close to one and can be determined using eq. 6 [28].

$S=\frac{1}{1-\left[4 \cdot g \cdot \gamma \cdot\left(\rho_{1}-\rho_{\mathrm{g}}\right) \cdot \rho_{\mathrm{g}}^{-2}\right]^{0.25}}$

Here $\rho_{\mathrm{l}}$ and $\rho_{\mathrm{g}}$ are the liquid and gas densities, $\gamma$ is the interfacial tension and $g$ is the acceleration due to gravity. The droplet average diameter and the droplet entrainment, $E$, were obtained from the following correlations for horizontal pipelines [29,30]: 
$d_{32}=0.128 \cdot\left(\frac{\sigma}{\rho_{\mathrm{g}}}\right)^{0.604} \cdot v_{\mathrm{g}}^{-1.209} \cdot D_{\mathrm{h}}^{0.396}$

$\frac{E}{E_{\mathrm{M}}-E}=A_{1} \cdot D_{\mathrm{h}} \cdot \frac{\sqrt{\rho_{\mathrm{g}} \cdot \rho_{\mathrm{l}}}}{\sigma} \cdot v_{\mathrm{g}}^{2}$

In these expressions, $v_{\mathrm{g}}$ is the gas velocity and $E_{\mathrm{M}}$ is the maximum value of the entrainment, which was calculated following the method discussed by Pan et al. [30]. The constant $A_{1}=3.6 \cdot 10^{-5}$ has been adjusted to entrainment data obtained by Mantilla et al. [31] using a high pressure gas-liquid flowloop, as described by Di Lorenzo et al. [18].

\subsection{Hydrate Deposition Model}

In this model it is assumed that, within each control volume corresponding to a segment of the pipe, hydrates deposits are uniformly distributed around the pipe wall perimeter. The rate at which the deposit accumulates, $\Delta V_{\text {dep }} / \Delta t$, results from the combined contribution of hydrates growing at the pipe wall $\Delta V_{\text {film }} / \Delta t$ and the hydrate particles depositing from the gas stream onto the wall, $\Delta V_{\text {part }} / \Delta t$.

$\frac{\Delta V_{\text {dep }}}{\Delta t}=\frac{\Delta V_{\text {film }}}{\Delta t}+\frac{\Delta V_{\text {part }}}{\Delta t}$

The first term in eq. 9 was calculated using eq. 3 with $A=A_{\text {film }}$ (eq.5). The second contribution was estimated as:

$\frac{\Delta V_{\text {part }}}{\Delta t}=\frac{F_{\mathrm{d}}}{S} \cdot \frac{\Delta V_{\mathrm{drop}}}{\Delta t}$

In eq. $10 \Delta V_{\text {drop }} / \Delta t$ is the rate of hydrate formation in the droplets, calculated using eq. 3 with $A=A_{\text {drop }}$ (eq. 4) and $F_{\mathrm{d}}$ is an empirical deposition efficiency factor, less than 1, which represents the probability that a particle sticks at the wall or hydrate layer. A derivation of this simplified expression, valid for particle deposition in the diffusional regime, is presented in Appendix C.

For the purpose of calculating the grow rate, we have assumed that the deposit is non-porous, even though it is partially made of hydrate particles. Furthermore the contribution to the particle volume of 
unconverted water or MEG solution, eventually occluded in the particle core, is neglected. Both assumptions could lead to an underestimation of the effective volume of the deposit when using eq. 10 to calculate the deposit growth rate.

Finally the change in the hydraulic diameter of the pipe was obtained from the growth rate of the hydrate deposit (eq. 9), by integration of eq. 11:

$\frac{\Delta V_{\mathrm{dep}}}{\Delta t}=-\frac{\pi}{4} \cdot \frac{\Delta D_{\mathrm{h}}^{2}}{\Delta t} \cdot \Delta x$

\subsection{Model for Hydrate Sloughing from the Pipe Wall}

The sloughing model assumes that the deposited film fractures under the increasing shear stress applied by the pipeline fluids as the effective hydraulic diameter decreases, and that fragments of the solid deposit break off and are released into the gas stream. A sloughing event causes the pressure drop signal to suddenly decrease due to the immediate enlargement of the hydraulic diameter of the pipe. The signal observed for such sloughing events typically dropped to a value well above that corresponding to the bare pipe wall, which indicated that the hydrate deposit was not completely stripped off the pipe wall.

To implement this conceptual model two main components need to be considered: the mechanical properties of the hydrate deposit and the hydrodynamic loading applied to the film. The model assumes that the hydrate deposit has a heterogeneous structure because it is composed of a low porosity crystalline film growing outwards from the pipe's inner wall, and a higher porosity layer due to hydrate particles deposited from entrained droplets. As the deposit ages, the high porosity layer may undergo a sintering process, leading to an increased adhesion strength between the deposited particles and the crystalline substrate. By assuming the deposit consists of two-layers (a compact substrate adhered at the pipe wall with an overlaying porous material), a weak zone, along which a fracture may develop, can be located at the moving boundary between the two layers. The hydrodynamic loading applied to this weak zone, due to the shear stress applied by the bulk fluids, is approximated as: 
$\sigma_{\mathrm{w}}=-\frac{D_{\mathrm{h}}}{4} \cdot \frac{\Delta P}{\Delta x}$

where $\sigma_{\mathrm{w}}$ is the wall shear stress and $\Delta P / \Delta x$ is the pressure gradient along the pipeline (eq. 1 ).

The model tracks the growth of the complete hydrate deposit and that of the stable film underneath ( $\Delta V_{\text {dep }} / \Delta t$ and $\Delta V_{\text {film }} / \Delta t$ respectively) and the evolution of the respective hydraulic diameters, using eq. 11. An empirical multiplicative factor to the kinetic growth rate of the stable film, $F_{\mathrm{f}}>1$, is introduced to increase the effective growth rate of the hard substrate above the kinetic rate, due to sintering of the deposited porous layer. At each point in space and time, the wall shear stress is calculated using eq. 12 and compared with the hydrate film shear strength, $\sigma_{\mathrm{h}}$ (critical shear stress for film rupture). The sloughing instant, $t_{\mathrm{s}}$, and sloughing point, $x_{\mathrm{s}}$, are determined, respectively, by the conditions:

$\sigma_{\mathrm{w}}(x, t)=\sigma_{\mathrm{h}}$

$D_{\mathrm{h}}\left(x, t_{\mathrm{s}}\right)=D_{\mathrm{f}}\left(x, t_{\mathrm{s}}\right)$

where $D_{\mathrm{f}}$ is the hydraulic diameter corresponding to the stable film. Then the values of the hydraulic diameter downstream the sloughing point are updated as follows:

$D_{\mathrm{h}}\left(x, t_{\mathrm{s}}\right)=D_{\mathrm{f}}\left(x, t_{\mathrm{s}}\right)$ if $x_{\mathrm{s}}<x<x\left(t_{\mathrm{s}}\right)$

$D_{\mathrm{h}}\left(x, t_{\mathrm{s}}\right)=D_{\mathrm{f}}(x, t)$ if $x>=x\left(t_{\mathrm{s}}\right)$

The sloughing conditions given by eqs. 13 and 14 are illustrated in Figure 2. The height and depth of the sloughing peaks produced by the model can be matched to those of the experimental traces by tuning the deposition parameter $F_{\mathrm{d}}$, the stable film growth parameter $F_{\mathrm{f}}$ and the value of the effective shear strength of the deposit, $\sigma_{\mathrm{h}}$. 


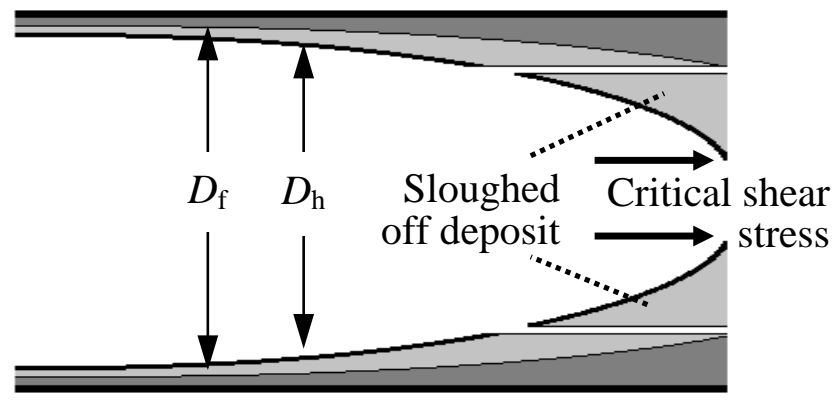

Figure 2. Conceptual picture of sloughing of the hydrate film at the pipe wall. (Darker grey: stable deposit, lighter grey: softer deposit, white line: fracture).

\section{Numerical scheme}

A flow diagram of the algorithm used to solve iteratively the model equations is represented in Figure 3. The numerical solution is obtained by discretising the pipeline in a number of sections of the same length. For manageable computation times, the number of sections was limited to a few hundred. For flow loop calculations, with 170 sections, each $0.2 \mathrm{~m}$ long, typical run times were of 300 seconds on a personal computer equipped with a $2.9 \mathrm{GHz}$ processor. Using 17 sections, the computation times decreased to 30 seconds and the relative deviations of the hydrate formation and deposition rates increased by $8 \%$ compared to the higher resolution run. The time step used was set by the ratio of the length of the pipe segment and the fluid mixture superficial velocity. This temporal resolution should be sufficient to describe hydrate growth and deposition given that they are slow processes compared with the residence time of the fluids in the pipe section.

Input data for this numerical algorithm were: the inner and outer pipe diameters, the total length of the pipeline and the length of pipe section; the ambient temperature, the inlet pressure and temperature; flow rates of gas and liquid; gas composition and MEG weight concentration in the liquid phase. The number of moles of each chemical component in the pipeline was calculated first, based on the gas and liquid composition, pressure, temperature and the initial liquid holdup. The required physical properties of the gaseous, liquid and solid phases, such as density, fluid viscosity, heat capacity, thermal conductivity and heat of hydrate formation were obtained from a thermodynamic package [32]. To account for the effect of 
composition, temperature and pressure on the fluid and hydrate properties, the requisite data were generated using Multiflash ${ }^{\circledR}$ [32] and polynomial interpolations were obtained in the range of the experimental conditions relevant to these tests.

In this model it was assumed that hydrates start to form as soon as the subcooling is larger than $0 \mathrm{~K}$ (pipeline temperature lower than hydrate equilibrium temperature). Higher minimum required subcooling values for the onset of hydrate formation have been reported in the literature, ranging from of 1 to $2 \mathrm{~K}$ (1.8 to $\left.3.6{ }^{0} \mathrm{~F}\right)$ in gas-condensate pipelines [2], up to $3.5 \mathrm{~K}\left(6.3^{0} \mathrm{~F}\right)$ in oil-dominated systems [3]. If the subcooling condition was satisfied, the total volume of hydrate formed and deposited at the pipe wall were calculated in each section (eqs. 3 and 9) and the local value of hydraulic diameter of the pipe section was deduced from eq. 11. In experimental tests where sloughing was observed, the sloughing conditions (eqs. 13 and 14) were applied and the hydraulic diameter was updated accordingly. At each pipe section the pressure and temperature were calculated from eqs. 1 and 2 using a forward difference scheme and the MEG concentration was updated according to the water consumption due to hydrate formation. Then the computational loop was iterated over the next time step until the experimental run-time expired. The model was coded using Visual Basic for Applications (VBA) within Microsoft Excel®. 


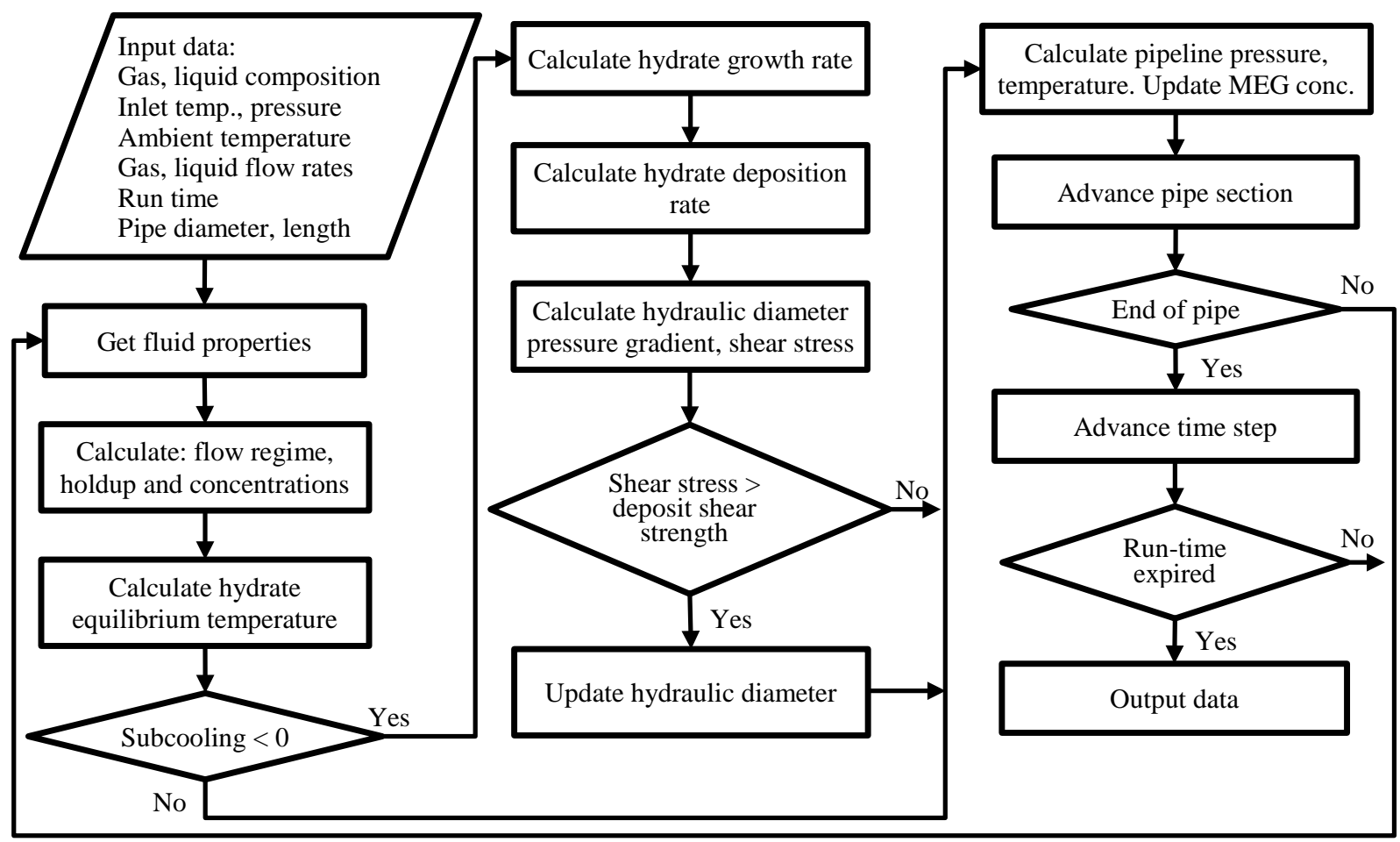

Figure 3. Flow diagram of the numerical model.

\section{Model Validation}

The model predictions were compared with results from previous experiments conducted in a one-pass, gas-dominant flowloop [17,18,23]. The pipeline fluids included natural gas, water and MEG. The composition of the gas used in these experiments is given in Table 1 . The values or functional dependences of the fluid and hydrate phase properties are summarized in Table 2. The flowloop outer and inner diameter and length were $D_{0}=0.025 \mathrm{~m}, D_{\mathrm{i}}=0.020 \mathrm{~m}$ and $\mathrm{L}=33.4 \mathrm{~m}$, respectively. The thermal conductivity of the pipe was $k_{\mathrm{p}}=16 \mathrm{~W} \cdot \mathrm{m}^{-1} \cdot \mathrm{K}^{-1}$ (stainless steel) and the external heat transfer coefficient $h_{0}=0.6 \mathrm{~J} \cdot \mathrm{kg}^{-1} \cdot \mathrm{K}^{-1}$ was estimated using eq. A.2.

Table 1. Domestic gas composition.

\begin{tabular}{|c|c|}
\hline Components & Mole Percent \\
\hline $\mathrm{CH}_{4}$ & 87.30 \\
\hline
\end{tabular}




\begin{tabular}{|c|c|}
\hline $\mathrm{C}_{2} \mathrm{H}_{6}$ & 6.02 \\
\hline $\mathrm{C}_{3} \mathrm{H}_{8}$ & 1.51 \\
\hline $\mathrm{i}-\mathrm{C}_{4} \mathrm{H}_{10}$ & 0.14 \\
\hline $\mathrm{n}-\mathrm{C}_{4} \mathrm{H}_{10}$ & 0.21 \\
\hline $\mathrm{i}-\mathrm{C}_{5} \mathrm{H}_{12}$ & 0.04 \\
\hline $\mathrm{n}-\mathrm{C}_{5} \mathrm{H}_{12}$ & 0.04 \\
\hline $\mathrm{C}_{6}$ & 0.02 \\
\hline $\mathrm{C}_{6+}$ & 0.02 \\
\hline $\mathrm{CO}_{2}$ & 2.30 \\
\hline $\mathrm{N}_{2}$ & 2.40 \\
\hline
\end{tabular}

Sixteen flowloop experiments were simulated in this work as shown in Table 3. Experiments 1 to 12 had a high gas superficial velocity of $8.8 \mathrm{~m} / \mathrm{s}(28.9 \mathrm{ft} / \mathrm{s})$, both in the absence of MEG (Experiments 1 to 7 : uninhibited, high velocity tests), and at increasing MEG concentrations (Experiments 8 to 12: underinhibited, high velocity tests). Experiments 13 to 16 were conducted at an intermediate gas velocity of 4.7 $\mathrm{m} / \mathrm{s}(15.4 \mathrm{ft} / \mathrm{s})$ in the absence of MEG (uninhibited, intermediate velocity tests). In all experiments the liquid holdup was between 5\% and 6\% and the flow regime was annular. Experiments 1, 3, 8, 9 and 12 were affected by sloughing. Further experimental details can be found in the original references $[17,18,23]$.

The values of the model parameters used in the simulations are shown in Table 3. Two values of the parameter $F_{\mathrm{k}}$ were chosen to obtain closer estimates of the experimental average hydrate formation rate depending on the gas velocity, $F_{k}=0.5$ for the high gas velocity experiments (except in exp. 11) and $F_{\mathrm{k}}=0.2$ at intermediate gas velocity. The deposition and sloughing parameters were fitted to the experimental pressure drop traces. The shear stress values reported in Table 3 correspond to the critical shear stress at which the deposit ruptures in the experiments were sloughing was observed, whereas, in the absence of sloughing, the maximum value shear stress is shown for comparison. The average hydrate formation rates obtained in the simulation runs are plotted against the experimental data in Figure 4. The numerical values of the hydrate formation rate and subcooling are also reported in Table 3, together with the corresponding experimental determinations. 
Table 2. Fluid and hydrate properties.

\begin{tabular}{|c|c|}
\hline \multicolumn{2}{|l|}{ Gas phase property } \\
\hline Average molar mass & $M_{\mathrm{g}} / \mathrm{kg} \mathrm{mol}^{-1}=0.018$ \\
\hline Density & $\begin{array}{l}\rho_{\mathrm{g}} / \mathrm{kg}^{-3}=-1.27 \times 10^{-7}(\mathrm{P} / \mathrm{Pa})(\mathrm{T} / \mathrm{K})+0.49(\mathrm{~T} / \mathrm{K})+4.79 \times 10^{-5}(\mathrm{P} / \mathrm{Pa})+ \\
-156.6\end{array}$ \\
\hline Compressibility & $\begin{array}{l}Z=-3.04 \times 10^{-5}(T / \mathrm{K})^{2}+7.47 \times 10^{-16}(P / \mathrm{Pa})^{2}-4.21 \times 10^{-11}(\mathrm{P} / \mathrm{Pa})(T / \mathrm{K})+ \\
+2.1 \times 10^{-2}(T / \mathrm{K})-1.5 \times 10^{-8}(\mathrm{P} / \mathrm{Pa})-2.54\end{array}$ \\
\hline Viscosity & $\mu_{\mathrm{g}} / \mathrm{Pa} \cdot \mathrm{s}=6.45 \times 10^{-9}(T / \mathrm{K})+7.36 \times 10^{-13}(\mathrm{P} / \mathrm{Pa})+5.555 \times 10^{-6}$ \\
\hline Thermal conductivity & $k_{\mathrm{g}} / \mathrm{W} \cdot \mathrm{m}^{-1} \cdot \mathrm{K}^{-1}=2.06 \times 10^{-9}(\mathrm{P} / \mathrm{Pa})+0.02025$ \\
\hline Heat capacity at constant pressure & $\begin{array}{l}C p_{\mathrm{g}} / \mathrm{J} \cdot \mathrm{K}^{-1} \mathrm{~kg}^{-1}=0.258(T / \mathrm{K})^{2}-1.68 \times 10^{-11}(P / \mathrm{Pa})^{2}-2.39 \times 10^{-6}(\mathrm{P} / \mathrm{Pa})(T / \mathrm{K}) \\
-1.41 \times 10^{2}(T / \mathrm{K})+1.16 \times 10^{-3}(\mathrm{P} / \mathrm{Pa})+1.93 \times 10^{4}\end{array}$ \\
\hline Joule-Thompson coefficient & $\beta_{\mathrm{JT}} / \mathrm{K} \cdot \mathrm{Pa}^{-1}=3.626 \times 10^{-6}$ \\
\hline \multicolumn{2}{|c|}{ Liquid phase property as a function of MEG wt $\%$ concentration } \\
\hline Molar mass of water and MEG & $M_{\text {water }} / \mathrm{kg} \cdot \mathrm{mol}^{-1}=0.018, M_{\text {meg }} / \mathrm{kg} \mathrm{mol}^{-1}=0.062$ \\
\hline Density & $\rho_{\mathrm{l}} / \mathrm{kg} \cdot \mathrm{m}^{-3}=0.919 C_{\mathrm{meg}}+998.36$ \\
\hline Viscosity & $\mu_{1} / \mathrm{Pa} \cdot \mathrm{s}=1.06 \times 10^{-6} C_{\mathrm{meg}}{ }^{2}+1.88 \times 10^{-5} C_{\mathrm{meg}}+1.23 \times 10^{-3}$ \\
\hline Thermal conductivity & $k_{1} / \mathrm{W} \cdot \mathrm{m}^{-1} \cdot \mathrm{K}^{-1}=-4.01 \times 10^{-4} C_{\mathrm{meg}}^{2}+0.0201 C_{\mathrm{meg}}+0.626$ \\
\hline Constant pressure heat capacity & $C p_{1} / \mathrm{J} \cdot \mathrm{K}^{-1} \mathrm{~kg}^{-1}=-13.0 C_{\mathrm{meg}}+4323.8$ \\
\hline Interfacial tension with gas phase & $\gamma / \mathrm{N} \cdot \mathrm{m}^{-1}=2.14 \times 10^{-6} C_{\mathrm{meg}}^{2}-3.36 \times 10^{-4} C_{\mathrm{meg}}+0.072$ \\
\hline \multicolumn{2}{|l|}{ Hydrate phase property } \\
\hline Hydrate density & $\rho_{\mathrm{h}} / \mathrm{kg} \cdot \mathrm{m}^{-3}=950$ \\
\hline Gas molar density in hydrate & $\rho_{\mathrm{g}}^{\mathrm{h}} / \mathrm{mole}^{\prime} \mathrm{m}^{-3}=7540$ \\
\hline Thermal conductivity & $k_{\mathrm{h}} / \mathrm{W} \cdot \mathrm{m}^{-1} \cdot \mathrm{K}^{-1}=0.6$ \\
\hline Heat capacity & $C p_{\mathrm{h}} / \mathrm{J} \cdot \mathrm{K}^{-1} \mathrm{~kg}^{-1}=-10.9 \mathrm{~T}+2257$ \\
\hline Enthalpy of formation & $\Delta H / \mathrm{J}^{\mathrm{kg}}{ }^{-1}=6.4 \times 10^{5}$ \\
\hline
\end{tabular}

The error bars in Figure 4 correspond to a relative uncertainty of $\pm 15 \%$.in hydrate formation rates [18]. As shown in Figure 4 in most cases the deviation of model predictions from the experimental data was less than $\pm 40 \%$. The model accuracy in reproducing the experimental pressure drop data is expressed as the mean absolute relative deviation between experimental and calculated time series of the pressure drop across the flowloop ( $\Delta P$ rel. deviation). These results are presented in the last column of Table 3 . 
Table 3. Summary of the flow loop simulations.

\begin{tabular}{|c|c|c|c|c|c|c|c|c|c|c|c|}
\hline \multirow[t]{2}{*}{ Exp. } & \multirow{2}{*}{$\begin{array}{c}C_{\mathrm{meg}} \\
(\mathrm{wt} \%)\end{array}$} & \multirow[t]{2}{*}{$F_{\mathrm{k}}$} & \multirow[t]{2}{*}{$F_{\mathrm{d}}$} & \multirow[t]{2}{*}{$F_{\mathrm{f}}$} & \multirow[t]{2}{*}{$\sigma_{\mathrm{h}} / \mathrm{Pa}$} & \multicolumn{2}{|c|}{$\Delta T_{\mathrm{sub}} / \mathrm{K}$} & \multicolumn{2}{|c|}{$\frac{\Delta V_{\mathrm{h}}}{\Delta t} / \mathrm{L} \cdot \min ^{-1}$} & \multirow[t]{2}{*}{$\frac{\Delta V_{\mathrm{dep}}}{\Delta t} / \mathrm{L} \cdot \mathrm{min}^{-1}$} & \multirow{2}{*}{$\begin{array}{c}\Delta P \text { rel. } \\
\text { deviation } \\
(\%)\end{array}$} \\
\hline & & & & & & Exp. & Model & Exp. & Model & & \\
\hline $1^{*}$ & 0 & 0.5 & 0.35 & 0.44 & 152 & 2.5 & 1.9 & 0.49 & 0.80 & 0.34 & 13.8 \\
\hline 2 & 0 & 0.5 & 0.05 & 1.00 & 155 & 4.3 & 4.0 & 0.56 & 0.73 & 0.12 & 13.3 \\
\hline $3^{*}$ & 0 & 0.5 & 0.06 & 0.80 & 124 & 4.4 & 4.0 & 0.48 & 0.78 & 0.14 & 13.9 \\
\hline 4 & 0 & 0.5 & 0.06 & 1.00 & 130 & 7.1 & 6.9 & 1.02 & 0.72 & 0.14 & 25.9 \\
\hline 5 & 0 & 0.5 & 0.05 & 1.00 & 106 & 6.8 & 6.8 & 0.55 & 0.76 & 0.14 & 27.2 \\
\hline 6 & 0 & 0.5 & 0.25 & 1.00 & 144 & 8.0 & 7.9 & 1.12 & 0.65 & 0.24 & 27.6 \\
\hline 7 & 0 & 0.5 & 0.19 & 1.00 & 124 & 8.8 & 8.4 & 0.91 & 0.66 & 0.22 & 39.7 \\
\hline $8^{*}$ & 10 & 0.5 & 0.24 & 0.40 & 117 & 3.1 & 3.0 & 0.29 & 0.46 & 0.16 & 9.1 \\
\hline $9 *$ & 20 & 0.5 & 0.84 & 0.45 & 186 & 1.8 & 1.8 & 0.20 & 0.22 & 0.20 & 9.6 \\
\hline $10^{*}$ & 20 & 0.5 & 0.33 & 0.90 & 124 & 4.6 & 4.4 & 0.35 & 0.35 & 0.15 & 15.6 \\
\hline 11 & 20 & 0.5 & 0.28 & 1.00 & 124 & 5.5 & 5.6 & 0.40 & 0.35 & 0.13 & 14.3 \\
\hline $12^{*}$ & 30 & 1.0 & 0.76 & 0.40 & 131 & 3.0 & 2.5 & 0.26 & 0.28 & 0.23 & 12.9 \\
\hline 13 & 0 & 0.2 & 0.25 & 1.00 & 22 & 4.5 & 4.1 & 0.03 & 0.05 & 0.04 & 21.6 \\
\hline 14 & 0 & 0.2 & 0.50 & 1.00 & 35 & 6.0 & 6.1 & 0.07 & 0.07 & 0.06 & 43.5 \\
\hline 15 & 0 & 0.2 & 0.78 & 1.00 & 50 & 7.0 & 6.9 & 0.10 & 0.07 & 0.07 & 51.5 \\
\hline 16 & 0 & 0.2 & 0.62 & 1.00 & 68 & 7.5 & 7.5 & 0.08 & 0.09 & 0.07 & 40.3 \\
\hline
\end{tabular}

*Experiments affected by sloughing 


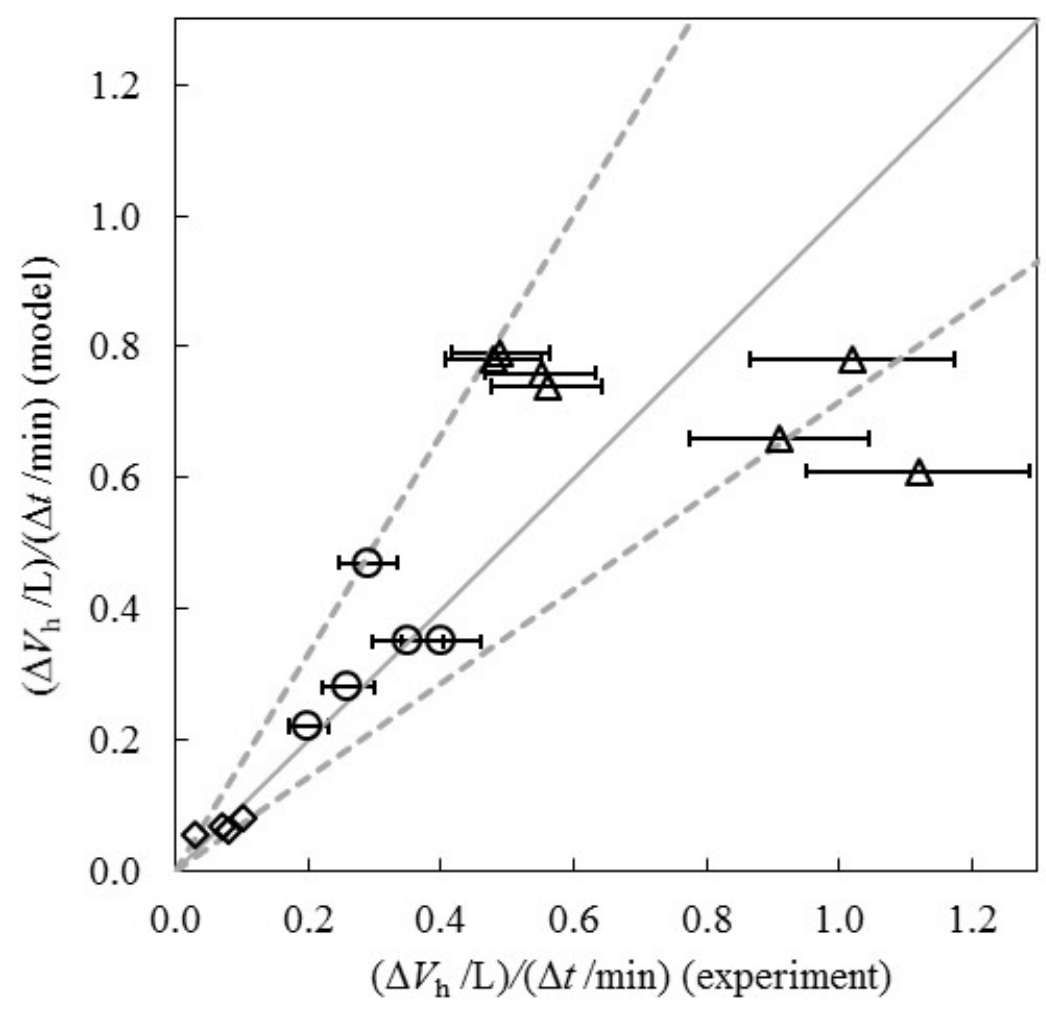

Figure 4. Model predictions for hydrate formation rates in the flowloop compared with experimental results. Dashed lines indicate the $\pm 40 \%$ deviation bounds. (Triangles: uninhibited, high velocity; circles: underinhibited, high velocity; diamonds: uninhibited, intermediate velocity).

The pressure drop, $\Delta P$, as a function of the time from liquid injection, $t$, and the average temperatures as a function of the distance from the location of the first thermometer, $x$, measured during experiment 2 are presented in Figure 5 and Figure 6 together with the corresponding experimental data. In this test, conducted at a relatively low subcooling of $4.3 \mathrm{~K}$, in the absence of MEG, the experimental pressure drop increased smoothly with time. A close match between the experimental data and the model results was obtained using a value of 0.05 for the deposition parameter. Similar values of the deposition parameter, in the range of 0.04 to 0.06 , were used by Wang et al. [22] in their model to fit baseline pressure drop data obtained in these flowloop tests. By setting the hydrate deposit shear strength value above 155 Pa no sloughing events were produced throughout the experimental run. 


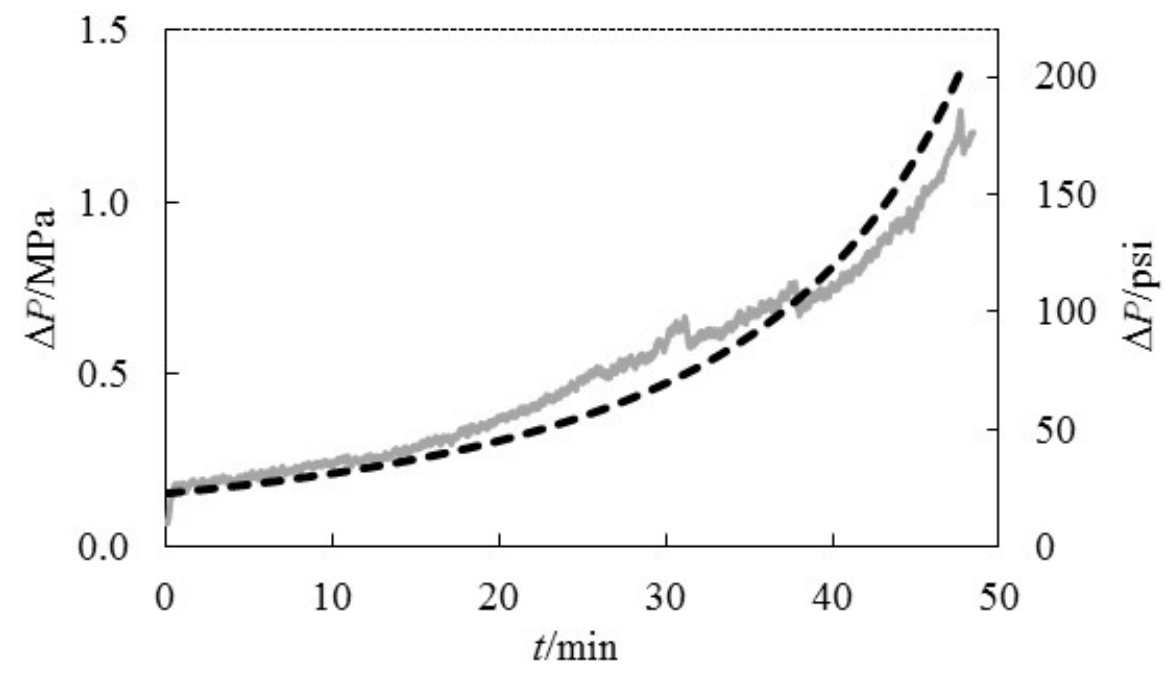

Figure 5. Pressure drop compared with the model prediction during experiment 2 in the absence of MEG at average subcooling of $4.3 \mathrm{~K}$ (grey line: experiment, dashed line: model).

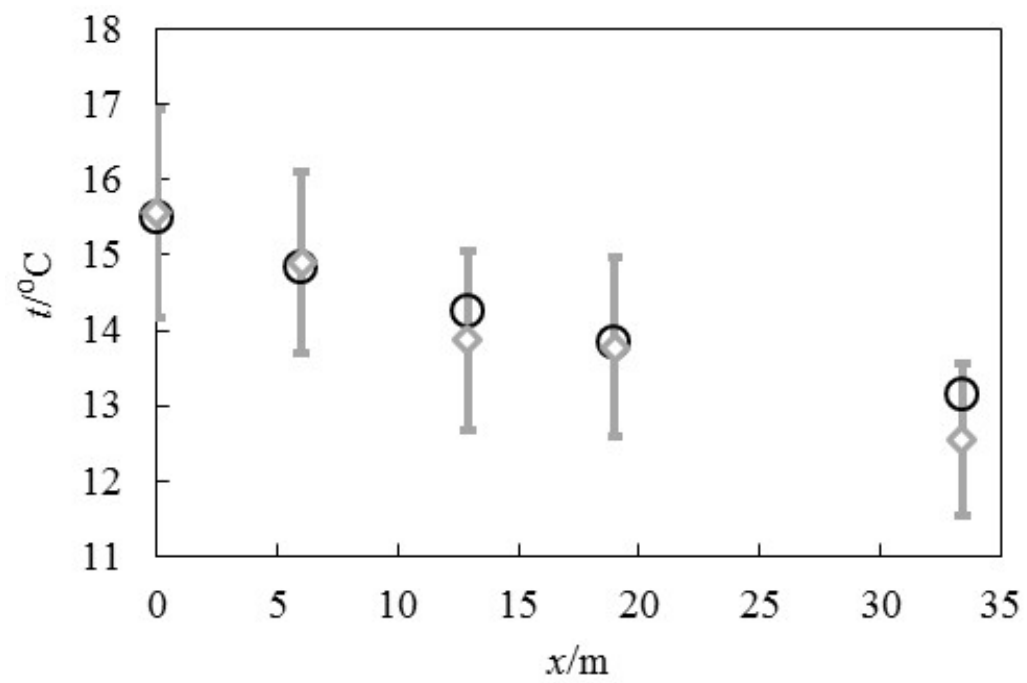

Figure 6. Temperature profile along the flowloop compared with the model prediction during experiment 2 in the absence of MEG (grey diamonds: experiment, black circles: model).

Figure 6 shows the time-averaged simulated and measured values of the temperature at the flowloop measuring points. The pipeline fluid temperatures decreased with the distance downstream the injection point as heat was exchanged with the coolant fluid maintained at a lower temperature of $12{ }^{\circ} \mathrm{C}\left(53.6^{\circ} \mathrm{F}\right)$. The model predictions agreed with the measured data within the uncertainty of these determinations, which was in the range of $\pm 1.0^{\circ} \mathrm{C}\left(1.8^{\circ} \mathrm{F}\right)[18]$. 
In Figure 7 the calculated and experimental pressure drop traces obtained for experiment 11 are compared. This test was performed in the presence of MEG at $20 \mathrm{wt} \%$ concentration at an average subcooling of $5.5 \mathrm{~K}$. The experimental trace was smooth throughout whole run and in this case the model reproduced its behaviour accurately with the deposition empirical parameter increased to a value of 0.28.

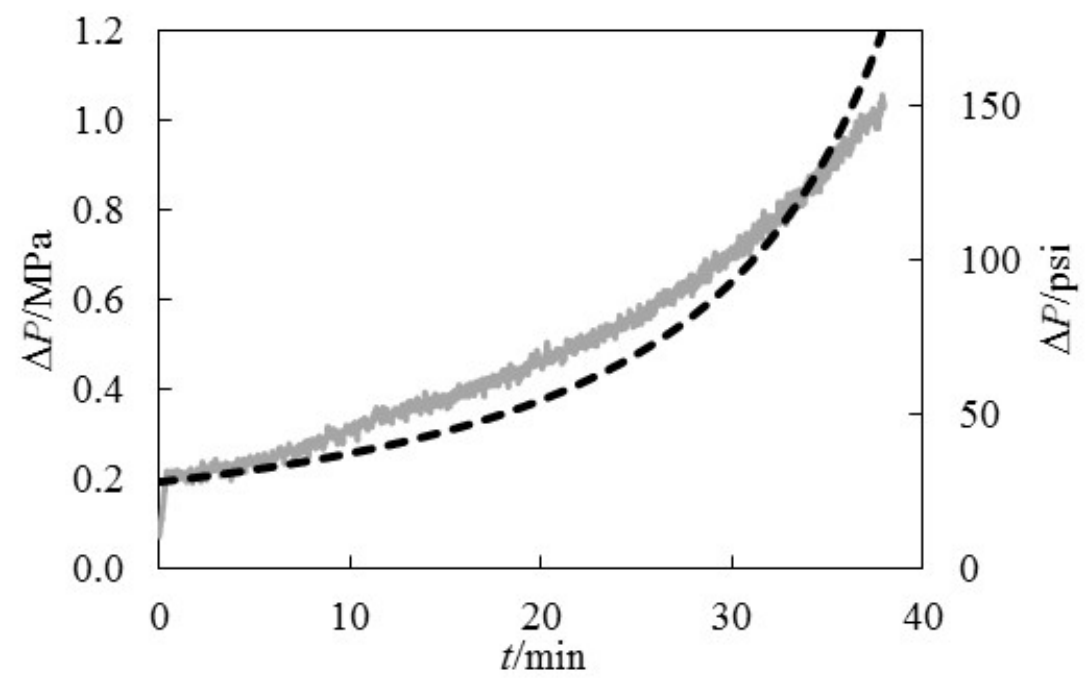

Figure 7. Pressure drop evolution compared with the model prediction for during experiment 11 conducted at a subcooling of $5.5 \mathrm{~K}$ and 20\% MEG wt. concentration (grey line: experiment, dashed line: model).

Experiments 13 and 15 were conducted in the absence of MEG and at an intermediate gas velocity of $4.7 \mathrm{~m} / \mathrm{s}(15.4 \mathrm{ft} / \mathrm{s}), 47 \%$ lower than in the previous experiments, but still with the system in the annular flow regime. The average subcoolings were 6 and $7.5 \mathrm{~K}$, respectively. The simulated pressure drop traces obtained in these tests, presented in Figure 8 and Figure 9, were obtained reducing the hydrate formation parameter to 0.2 and an increasing the deposition parameter to 0.5 and 0.62 respectively. The results presented in Figure 8 and Figure 9 presented higher values of the mean relative deviations of the pressure drop, as reported in Table 3, which indicates that, at lower gas velocity, the model becomes less accurate in reproducing the pressure drop behaviour compared with the uninhibited tests at high gas velocity. During the initial transient period the experimental pressure drop was consistently higher than predicted by the model. Furthermore significant pressure drop signal fluctuations were observed throughout the 
experimental run, which the model cannot capture, as the deposition mechanisms at reduced gas velocities may result in inhomogeneous phase distribution across the pipeline section.

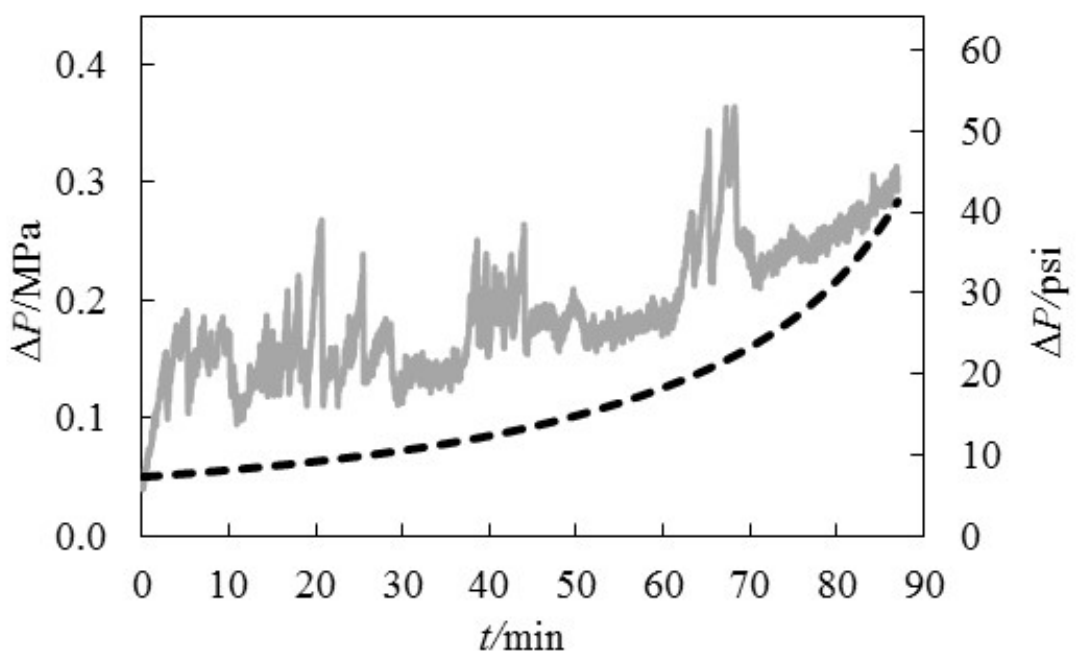

Figure 8. Pressure drop during experiment 14 at gas velocity of $4.7 \mathrm{~m} / \mathrm{s}(15.4 \mathrm{ft} / \mathrm{s})$ and subcooling of $6 \mathrm{~K}$ compared with the model prediction (grey line: experiment, dashed line: model).

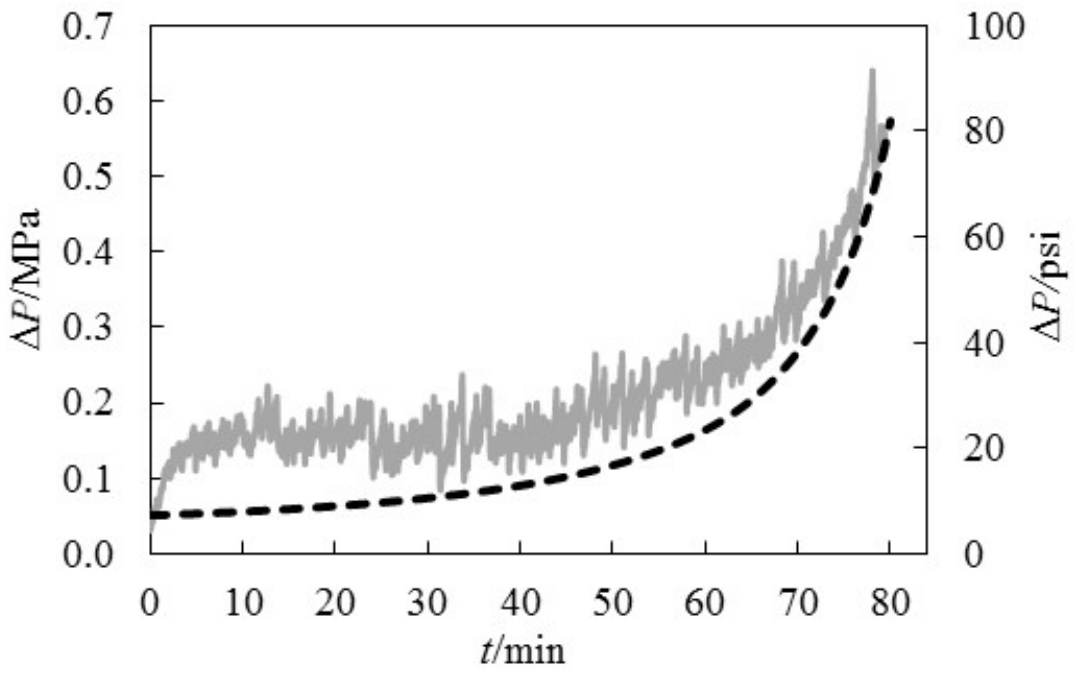

Figure 9. Pressure drop during experiment 16 at gas velocity of $4.7 \mathrm{~m} / \mathrm{s}(15.4 \mathrm{ft} / \mathrm{s})$ and a subcooling of 7.5 $\mathrm{K}$, compared with the model prediction (grey line: experiment, dashed line: model).

Despite these limitations, the model could reproduce quantitatively the impact of the gas velocity on the plugging tendency of these systems by predicting an order of magnitude decrease in the hydrate formation rate and a three-fold reduction in the deposition rate under similar subcooling conditions. This 
remarkable drop in the formation rate was mostly due to the decrease in the liquid entrainment at lower gas velocities, which resulted in a three to four fold decrease in the gas-liquid interfacial area [23].

\subsection{Effect of Sloughing}

In five high gas velocity experiments (1, 3, 8, 9, 12 in Table 3), performed at relatively low subcooling conditions, one or several peaks were observed in each pressure drop trace, which were attributed to sloughing events. In an effort to reproduce this complex behaviour, the empirical parameters describing deposition, $F_{d}$, crystalline film growth, $F_{f}$, and the effective shear strength of the deposit, $\sigma_{h}$, were adjusted to fit the first peak and evolution of the baseline of the pressure drop signal. As previously described in the sloughing model, the shear strength of the hydrate deposit corresponds to the shear stress applied by the fluids at the point of rupture and its value determines the height of the pressure drop peak. The crystalline film growth parameter represents the volume fraction of the deposited particles that undergoes sintering, contributing to the formation of the stable part of the hydrate deposit. Typical results obtained from this fitting procedure are presented in Figure 10 for experiment 1 (uninhibited system) and Figure 11 for experiment 12 (under-inhibited system). The kinetic parameter $F_{k}$ was set at 0.5 , as in the previous simulations, nevertheless, in the simulation of experiment 12, the deposition rate was too low to reproduce the first peaks (see Figure 11, dashed line), even if the deposition parameter was set at its maximum value of 1 . In a second run, using $F_{k}=1.0$, the predicted and measured formation rates agreed, and the model could be fitted to the first pressure drop peak. 


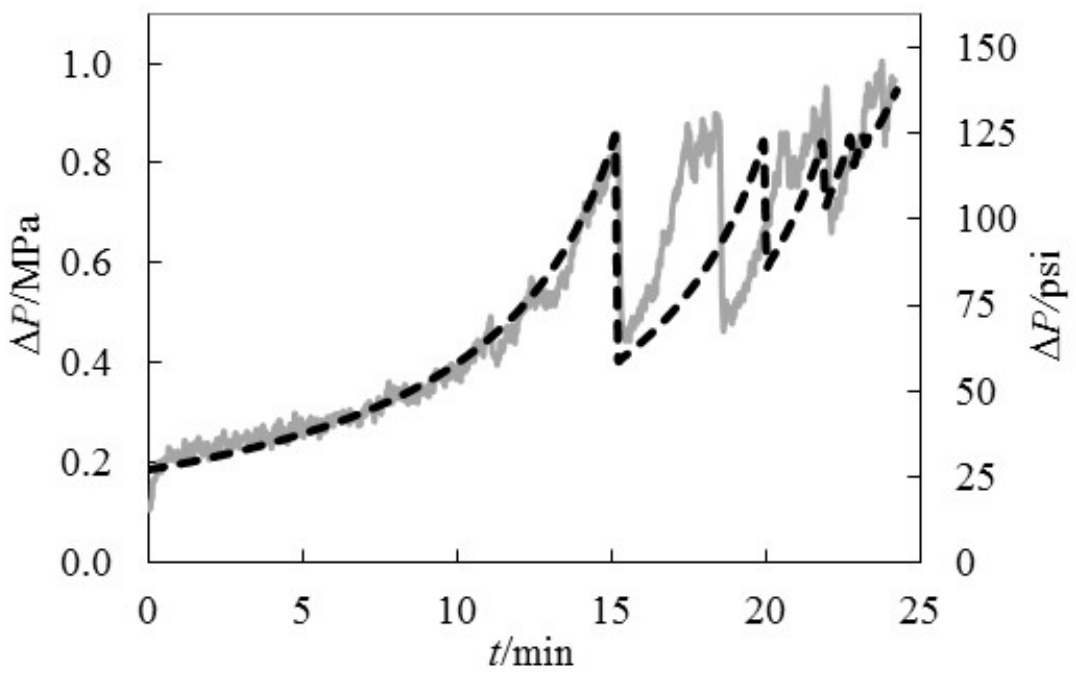

Figure 10. Model prediction against experimental data for the pressure drop in experiment 1 (grey line: experiment, dashed line: model, $\left.F_{k}=0.5\right)$.

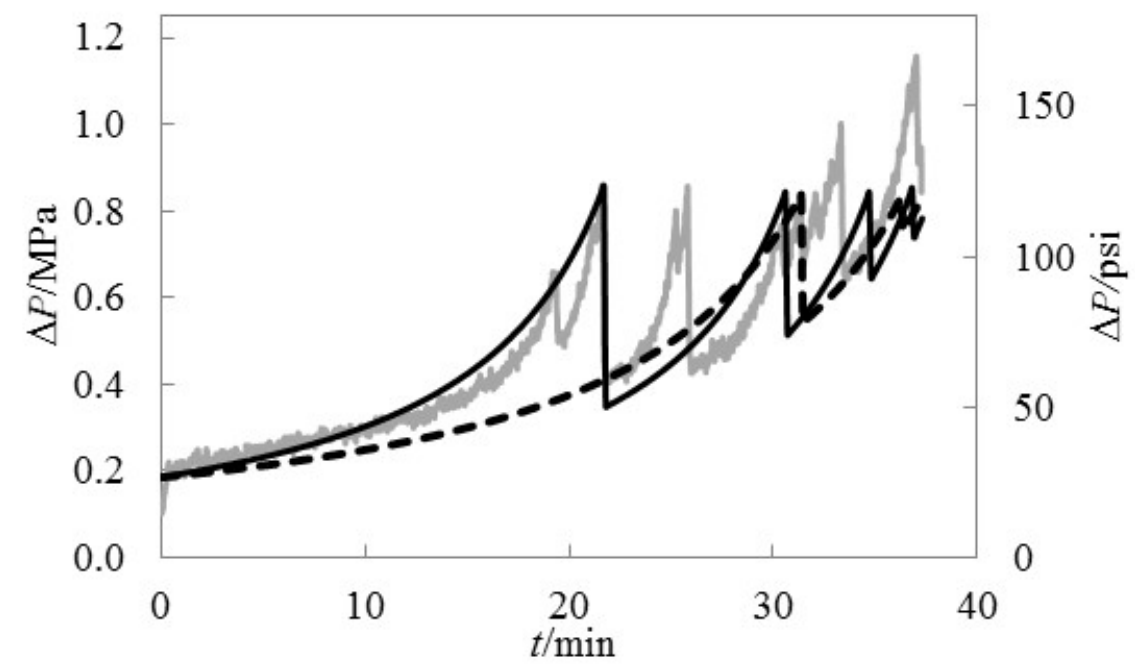

Figure 11. Model prediction against experimental data for the pressure drop in experiment 12 (grey line) using two values the kinetic parameter: $F_{k}=0.5$ (black dashed line) and $F_{k}=1.0$ (black continuous line).

The results show that the integrated model can provide a more accurate estimate of the pressure drop evolution at low subcooling than previous approaches based on continuous hydrate film growth [18,22], as, unlike previous models, it is capable of reproducing the observed sequence of sloughing events reasonably well, particularly considering its underlying simple assumptions. The hypothesis of a uniform 
two-film growth on the pipe wall represents only a first approximation to the structure and evolution of the hydrate deposit, which is governed by the combination of complex phenomena such kinetic growth at the pipe wall, particle deposition and sintering. On the other hand, the model's approximation of the hydrodynamic loading as an average value of the wall shear stress (eq. 12) does not consider the natural fluctuations arising from the pipeline turbulent flow and the wake shedding from the deposit roughness. A probabilistic approach based on the statistical theory of material strength could possibly be used to model explicitly the hydrate deposit failure under fluctuating loadings and provide a more realistic representation of the sloughing process.

\subsection{Model parameters}

The model relies on a set of physical parameters that currently are not well understood. More fundamental studies are required to elucidate the effects of heat and mass transfer resistances on hydrate growth on entrained droplets. Here it is implicitly assumed that these effects are relatively small and hydrate growth is governed by an intrinsic kinetic mechanism driven by the subcooling. The relatively high values of the kinetic model parameter $F_{k}(0.2$ to 1$)$ suggest that this may be an acceptable approximation. Nevertheless the decrease of the kinetic parameter obtained with at lower gas velocity suggests that a mass transfer limited model for hydrate growth [33] may be more appropriate when transitioning towards the stratified wavy regime. The implementation of mass transfer limited models to simulate hydrate formation in pipelines [34] though may be computational demanding as it is based on compositional tracking.

The probability of particle adhesion, expressed by the particle deposition parameter, depends on the balance of the adhesion forces between the depositing particles and the substrate and the hydrodynamic forces close to the hydrate deposit surface. The adhesion forces are mainly determined by the particle size and particle-substrate interactions, such capillary forces, which are strongly influenced by the subcooling [35] and the presence of MEG. In a study on the plugging tendencies of under-inhibited systems with MEG using a flow simulator [36], it was found that the hydrate dispersion characteristics were mainly 
determined by the MEG concentration in three different regions: in the lower range (0 to 10 wt\%) hydrates formed large, dry aggregates; in the intermediate range (5 to $20 \mathrm{wt} \%$ ) larger, more adhesive lumps were observed, mostly deposited at the pipe wall; in the highest range ( $>20 \mathrm{wt} \%$ ) small hydrate particles formed a gel-like structure in the bulk fluid. These observations suggest that the adhesive/cohesive forces in under-inhibited systems tend to increase with MEG concentration, which is consistent with the behaviour of the model deposition factor used in our simulations. As shown in Figure 12 , the value of $F_{d}$ in simulations at closely matched subcooling conditions $\left(\Delta T_{\text {sub }}=3.9 \pm 0.8 \mathrm{~K}\right)$ increases significantly with the MEG concentration in the range from 0 to $30 \mathrm{wt} \%$, which reflects a higher deposition tendency of hydrate particles, due to the formation of capillary bridges on the hydrate substrate or the pipe wall.

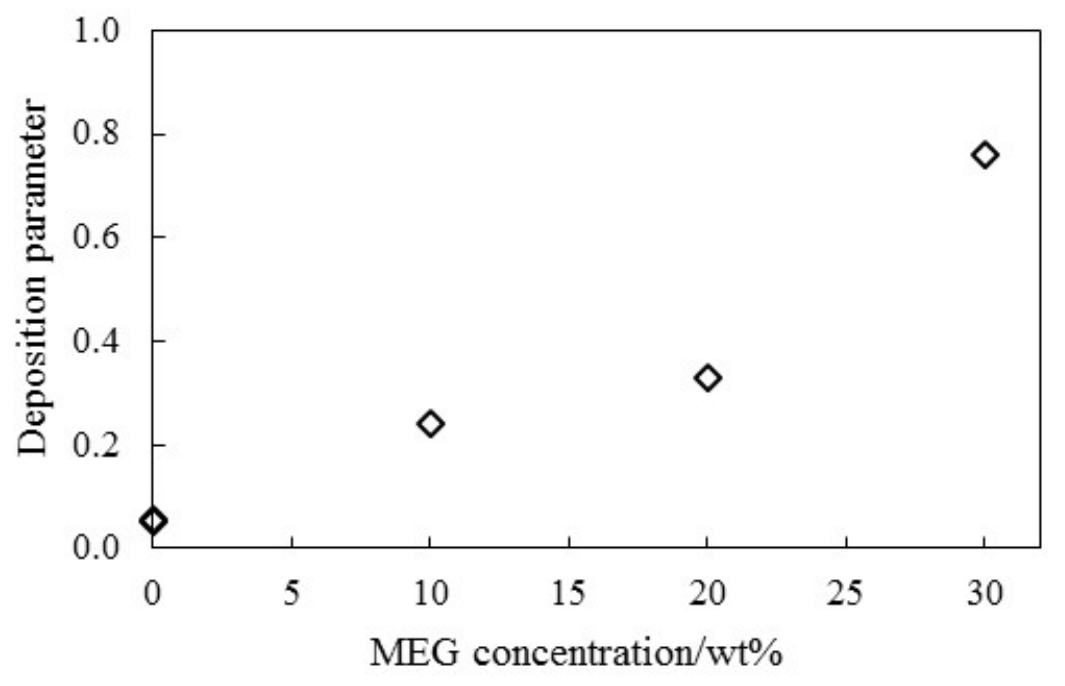

Figure 12. Deposition parameter from simulation of experiments 2, 3, 8, 10, 12 conducted at subcooling conditions in the interval $3.9 \pm 0.8 \mathrm{~K}$ and increasing MEG concentration.

The determination of the shear strength of the hydrate deposit from our fitting procedure applied to the pressure drop traces affected by sloughing is one of the most relevant results obtained from this study. The values of the shear strength parameter, reported for the first time in this work, are in the range of 100$200 \mathrm{~Pa}$, which are in the same order of magnitude of those obtained from direct measurements on dry, coherent snow, reported by Mellor [37], at a low density of $0.15 \mathrm{~g} / \mathrm{cm}^{3}$. As shown by the author, the shear 
strength could increase up to three orders of magnitude in more dense snow, nevertheless the presence of water is likely have a weakening effect in these systems [38].

\section{Conclusions}

A computational algorithm was developed for hydrate deposition and sloughing in gas-dominated pipelines in the annular flow regime using a semi-empirical, one-dimensional model. In this model the Beggs and Brill method for multiphase flow and pressure-gradient prediction was extended by allowing the hydraulic diameter of the pipe to vary due to hydrate deposition at the pipe wall and sloughing. Two main empirical parameters were introduced: a scaling factor to the intrinsic hydrate formation rate, $F_{k}$, and deposition efficiency factor, $F_{d}$, which accounts for the probability of particle adhesion. The tuned model was capable of predicting the rates of hydrate formation previously obtained in flow loop experiments under annular flow conditions in the presence of MEG (0 to $30 \mathrm{wt} \%$ ) within $\pm 40 \%$ of the measured rates. The time-averaged relative deviation of the simulated pressure drop from the experimental flowloop data varied between 9 and $40 \%$ at high gas velocity, increasing to $50 \%$ at intermediate gas velocity. The effect of the gas velocity in these experiments was correctly simulated by the model, where a $50 \%$ reduction in the gas flow rate resulted in an order of magnitude decrease in the hydrate formation rate and a three-fold reduction in the deposition rate under similar subcooling conditions.

The preliminary model for shear-induced sloughing in gas-dominated systems, introduced for the first time in this study, was capable of capturing the sequence of sloughing events observed in the flowloop pressure drop traces and allowed to obtain a more accurate estimation of the pressure drop behaviour in low subcooling conditions when sloughing was prevalent compared to previous models based on continuous deposit growth. An important outcome from this analysis was the estimation of the effective shear strength of the hydrate deposit, introduced as an additional model parameter to fit the pressure drop

peaks associated with sloughing events. This mechanical property of hydrate deposits is essential to develop future computational tools capable to predict when and where sloughing events will occur, their severity and potential to plug gas pipelines. 


\section{Acknowledgements}

The authors acknowledge the Commonwealth Scientific and Industrial Research Organization (CSIRO) of Australia for permission to publish this paper and the Australian Research Council (ARC) for their support through the grant IC150100019.

\section{APPENDIX A}

The overall heat transfer coefficient $U$ is calculated as a series of internal and external convective resistances, and the conductive resistances through the pipe and the hydrate deposit:

$$
U^{1}=\frac{1}{h_{\mathrm{i}}}+\frac{D_{\mathrm{h}}}{2 \gamma_{\mathrm{h}}} \ln \left(\frac{D_{\mathrm{i}}}{D_{\mathrm{h}}}\right)+\frac{D_{\mathrm{h}}}{2 \gamma_{\mathrm{p}}} \ln \left(\frac{D_{\mathrm{o}}}{D_{\mathrm{h}}}\right)+\frac{D_{\mathrm{h}}}{D_{\mathrm{o}} h_{\mathrm{o}}}
$$

Here $\gamma_{\mathrm{h}}$ and $\gamma_{\mathrm{p}}$ are the thermal conductivities of the hydrate and the pipe wall, respectively; $D_{\mathrm{i}}$ and $D_{\mathrm{o}}$ are the inner and outer diameters of the pipe, respectively; and $h_{\mathrm{i}}$, and $h_{\mathrm{o}}$ are the inner and outer heat transfer coefficients, respectively. These heat transfer coefficients are determined from eq. A.2, using the thermal conductivity of the pipeline and external fluids, $\gamma_{m}$ and $\gamma_{c}$, and the Nusselt number, $N u$, which is given by the Dittus-Boelter correlation [39] in eq. A.3:

$$
\begin{aligned}
& h_{\mathrm{i}, \mathrm{o}}=N u_{\mathrm{i}, \mathrm{o}} \cdot \frac{\gamma_{\mathrm{m}, \mathrm{c}}}{D_{\mathrm{h}}} \\
& N u_{\mathrm{i}, \mathrm{o}}=0.023 \operatorname{Re}_{\mathrm{i}, \mathrm{o}}^{0.88} \operatorname{Pr}_{\mathrm{i}, \mathrm{o}}^{0.3}
\end{aligned}
$$

In eq. A.3, $R e_{\mathrm{i}, \mathrm{o}}$ and $P r_{\mathrm{i}, \mathrm{o}}$ are the Reynolds and Prandtl numbers for the fluids inside and external to the pipeline, respectively:

$$
\begin{aligned}
& \operatorname{Re}_{\mathrm{i}, \mathrm{o}}=\frac{\rho_{\mathrm{m}, \mathrm{c}} v_{\mathrm{m}, \mathrm{c}} D_{\mathrm{h}}}{\mu_{\mathrm{m}, \mathrm{c}}} \\
& P r_{\mathrm{i}, \mathrm{o}}=\frac{c_{\mathrm{m}, \mathrm{c}} \cdot \mu_{\mathrm{m}, \mathrm{c}}}{\gamma_{\mathrm{m}, \mathrm{c}}}
\end{aligned}
$$

where $\mu_{\mathrm{m}, \mathrm{c}}$ indicates the dynamic viscosity of the pipeline and external fluids. 


\section{APPENDIX B}

A rapid estimation of the subcooling can be obtained using eq. B.1:

$\Delta T_{\mathrm{sub}}=t-\left(t_{\mathrm{eq}}^{0}-\Delta t_{\mathrm{MEG}}\right)$

where $t$ is the local pipeline temperature, $t_{\mathrm{eq}}^{0}$ is the hydrate equilibrium temperature at the local pipeline pressure in the absence of inhibitors and $\Delta t_{\mathrm{MEG}}$ is the shift in the equilibrium temperature due to the presence of MEG. For the gas composition used in the flowloop experiments (Table 1), the hydrate equilibrium temperature data obtained using CPA hydrate model [27] in the absence of MEG was fitted to eq. B.2:

$t_{\mathrm{eq}}^{0}=\left[-0.00010 \ln \left(-29.55+125.82 P-2.991 P^{2}\right)+0.00411\right]^{-1}-273.15$

in the range of temperatures between 4 and $20^{\circ} \mathrm{C}$ and pressures between 1.4 and $13 \mathrm{MPa}$, with a maximum deviation of $\pm 0.1^{\circ} \mathrm{C}$.

The shift in the hydrate equilibrium temperature in the presence of MEG was estimated using the Nielsen-Bucklin equation [12]:

$\Delta t_{\mathrm{MEG}}=-72 \ln \left[\alpha_{\mathrm{w}} \cdot\left(1-x_{\mathrm{MEG}}\right)\right]$

where $\alpha_{\mathrm{w}}$ is the water activity and $x_{\mathrm{MEG}}$ the molar concentration of MEG in the aqueous phase.

The water activity in the MEG solution was calculated using a two-suffix Margules expression [40]:

$\ln \left(\alpha_{\mathrm{w}}\right)=-1.84825 x_{\mathrm{MEG}}^{2}+4.26904 x_{\mathrm{MEG}}^{3}$

\section{APPENDIX C}

The deposition rate is calculated in eq. C.1 as the product of the volumetric flux of hydrate particles depositing at the wall, the surface area of the pipe section and the empirical deposition factor, $F_{\mathrm{d}}$.

$\frac{\Delta V_{\text {part }}}{\Delta t}=\left(\mathrm{v}_{\mathrm{dep}} C_{\mathrm{h}}^{\mathrm{g}}\right)\left(\pi D_{\mathrm{h}} \Delta x\right) F_{\mathrm{d}}$

Here the particle flux is expressed as the product of the particle deposition velocity, $v_{\text {dep }}$ and the volume fraction of hydrate particles in the gas phase, $c_{\mathrm{h}}{ }^{\mathrm{g}}$. 
The volume of hydrates in the gas is estimated as the product of the hydrate formation rate in the droplets $\Delta V_{\text {drop }} / \Delta t$ (eq. 3 with $A=A_{\text {drop }}$ ) and the droplet life time, $t_{\text {drop }}$, which, in the diffusional deposition regime, can be approximated as [41]:

$t_{\mathrm{drop}}=\frac{D_{\mathrm{h}}}{4 S v_{\mathrm{dep}}}$

Therefore, the concentration of hydrates in the gas phase is given by:

$c_{h}^{g}=\frac{\Delta V_{\mathrm{drop}}}{\Delta t} \frac{1}{\pi D_{\mathrm{h}} \Delta x S v_{\mathrm{dep}}}$

By substituting in eq. C.1, the following simplified expression for the deposition rate is obtained:

$\frac{\Delta V_{\text {part }}}{\Delta t}=\frac{\Delta V_{\text {drop }}}{\Delta t} \frac{F_{\mathrm{d}}}{S}$ 


\section{References}

[1] E.D. Sloan, Hydrate Engineering, Richardson, Texas, 2000.

[2] T. Austvik, E. Hustvedt, L.H. Gjertsen, O. Urdhal, Formation and removal of hydrate plugs - Field trial at Tommeliten Annual Convention Gas Processors Association, San Antonio, Texas, USA, 1997, pp. 205-211.

[3] P.N. Matthews, P.K. Notz, M.W. Widener, G. Prukop, Flow loop experiments determine hydrate plugging tendencies in the field, ANNALS NEW YORK ACADEMY OF SCIENCES 912 (2000) 330-338.

[4] J.L. Creek, Efficient hydrate plug prevention, Energy \& Fuels 26 (2012) 4112-4116.

[5] E.D. Sloan, A changing hydrate paradigm - from apprehension to avoidance to risk management, Fluid Phase Equilibria 228-229 (2005) 67-74.

[6] J.L. Creek, S. Subramanian, D. Estanga, New method for managing hydrates in deepwater tiebacks, SPE Offshore Technology Conference (2011).

[7] L.E. Zerpa, Z.M. Aman, S. Joshi, I. Rao, E.D. Sloan, C.A. Koh, A.K. Sum, Predicting hydrate blockages in oil, gas and water-dominated systems, Offshore Technology Conference, Houston, Texas, 2012.

[8] S.R. Davies, J.A. Boxall, C.A. Koh, E.D. Sloan, P.V. Hemmingsen, K.J. Kinnari, Z.G. Xu, Predicting hydrate plug formation in a subsea tieback, SPE 115763 (2008).

[9] Z.M. Aman, L.E. Zerpa, C.A. Koh, A.K. Sum, Development of a tool to assess hydrate-plugformation risk in oil-dominant pipelines, SPE Journal August (2015) 884-892.

[10] E.D. Sloan, C.A. Koh, A.K. Sum, Natural Gas Hydrates in Flow Assurance, Elsevier Inc., Oxford, UK, 2011.

[11] M.N. Lingelem, A.I. Majeed, E. Stange, Industrial experience in evaluation of hydrate formation, inhibition and dissociation in pipeline design and operation, Annals of the New York Academy of Sciences 175 (1994) 75-93.

[12] E.D. Sloan, C.A. Koh, Clathrate Hydrates of Natural Gases, Third ed., Taylor \& Francis Group, Boca Raton, FL, 2008.

[13] V.S. Shagapov, N.G. Musakaev, R.R. Urazov, Mathematical model of natural gas flow in pipelines with allowance for the dissociation of gas hydrates, Journal of Engineering Physics and Thermophysics 81 (2008) 287-296.

[14] J.W. Nicholas, C.A. Koh, E.D. Sloan, A preliminary approach to modelling gas hydrate/ice deposition from dissolved water in a liquid condensate system, AIChE Journal 55 (2009) 1889-1897.

[15] I. Rao, C.A. Koh, E.D. Sloan, A.K. Sum, Gas hydrate deposition on a cold surface in water-saturated gas systems, Industrial \& Engineering Chemistry Research 52 (2013) 6262-6269.

[16] F. Dorstewitz, D. Mewes, The influence of heat transfer on the formation of hydrate layers in pipes, International Journal of Heat and Mass Transfer 37 (1994) 2131-2137.

[17] M. Di Lorenzo, Z.M. Aman, G. Sanchez Soto, M. Johns, K.A. Kozielski, E.F. May, Hydrate formation in gas-dominant systems using a single-pass flowloop, Energy \& Fuels 28 (2014) 30433052.

[18] M. Di Lorenzo, Z.M. Aman, K. Kozielski, W.E.N. Bruce, M.L. Johns, E.F. May, Underinhibited hydrate formation and transport investigated using a single-pass gas-dominated flowloop, Energy \& Fuels 28 (2014) 7274-7284. 
[19] C. Cassar, A. Sinquin, A. Teixeira, P. Glenat, J.P. Leininger, Hydrate formation in gas dominant systems: influence of the flow pattern, 12th Offshore Mediterranean Conference and Exhibition, Ravenna, Italy, 2015.

[20] A. Sinquin, C. Cassar, A. Teixeira, J.P. Leininger, P. Glenat, Hydrate formation in gas dominant systems, Offshore Technology Conference, Texas, USA, 2015.

[21] Z. Wang, Y. Zhao, B. Sun, l. Chen, J. Zhang, X. Wang, Modelling of hydrate blockage in gasdominated systems, Energy \& Fuels 30 (2016) 4653-4666.

[22] Z. Wang, J. Zhang, B. Sun, L. Chen, Y. Zhao, W. Fu, A new hydrate deposition prediction model for gas-dominated systems with free water, Chemical Engineering Science 163 (2017) 145-154.

[23] Z.M. Aman, M. Di Lorenzo, K. Kozielski, C.A. Koh, P. Warrier, M.L. Johns, E.F. May, Hydrate formation and deposition in a gas-dominant flowloop: Initial studies on the effect of velocity and subcooling, Journal of Natural Gas Science and Engineering 35 (2016) 1490-1498.

[24] J.P. Brill, H.D. Beggs, Multiphase flow in wells, Richardson, Texas, 1999.

[25] I.N. Alves, F.J.S. Alhanati, O. Shoham, Flowing temperature distribution in wellbores and pipelines, SPE Production Engineering (1992) 363-367.

[26] D.J. Turner, J. Boxall, S. Yang, D.M. Kleehammer, C.A. Koh, K.T. Miller, E.D. Sloan, Development of a hydrate kinetic model and its incorporation into OLGA 2000 transient multiphase flow simulator, 5th International Conference on Gas Hydrates, Trondheim, Norway, 2005, pp. 1231-1240.

[27] Infochem, Multiflash for Windows, in: I.C.S. Ltd (Ed.), London, UK, 2012.

[28] M. Ishii, N. Zuber, Drag coefficient and relative velocity in bubbly, droplet or particulate flows, AIChE Journal 25 (1979) 843-855.

[29] A. Al-Sarkhi, T.J. Hanratty, Effect of pipe diameter on the drop size distribution in a horizontal annular gas-liquid flow, International Journal of Multiphase Flow 28 (2002) 1617-1629.

[30] L. Pan, T.J. Hanratty, Correlation of entrainment for annular flow in horizontal pipes, International Journal of Multiphase Flow 28 (2002) 385-408.

[31] I. Mantilla, F. Viana, G.E. Kouba, R. Roberts, Experimental investigation of liquid entrainment in gas at high pressure, in: B. Group (Ed.), Multiphase 8, 2012, pp. 211-224.

[32] Multiflash ${ }^{\circledR}$ for Windows, Infochem, London, 2012.

[33] P. Skovborg, P. Rasmussen, A mass transport limited model for the growth of methane and ethane gas hydrates, Chemical Engineering Science 49 (1994) 1131-1143.

[34] J. Sonne, K.S. Pedersen, Simulation of hydrate growth in steady state flow lines, in: B. group (Ed.), Multiphase Production Technology 14, 2009, pp. 361-373.

[35] Z.M. Aman, E.P. Brown, E.D. Sloan, A.K. Sum, C.A. Koh, Interfacial mechanisms governing cyclopentane clathrate hydrate adhesion/cohesion, Physical Chemistry Chemical Physics 2011 (2011) 19796-19806.

[36] P.l.V. Hemmingsen, L. X., K.J. Kinnari, Hydrate plugging potential in underinhibited systems, 6th International Conference on Gas Hydrates, Vancouver, British Columbia, Canada, 2008, pp. 1-12.

[37] M. Mellor, A review of basic snow mechanics, in: I.-A. Publication (Ed.), The International Symposium on Snow Mechanics, International Association of Hydrological Sciences, 1975, pp. 251291. 
[38] S. Trautmann, E. Lutz, ;, K. Birkeland, S. Custer, Releating wet loose snow avalanching to surficial shear strength, Proceedings International Snow Science Workshop, telluride, CO, USA, 2006, pp. 7178.

[39] F.P. Incropera, D.P. DeWitt, Fundamentals of heat and mass transfer, 4th ed., New York, 2000.

[40] G.D. Holder, S.P. Zetts, N. Pradhan, Phase behavior in systems containing clathrate hydrates, Reviews in Chemical Engineering 5 (1988) 1-70.

[41] P. Andreussi, B.J. Azzopardi, Droplet deposition and interchange in annular two-phase flow, International Journal of Multiphase Flow 9 (1983) 681-695. 